\title{
DISPLAY OF TOBACCO SALES WARNING SIGNS
}

Steven Hatzi, Environmental Health Officer

Santo Cannata, Senior Environmental Health Officer Michael J Fett, Director

Public Health Unit for Central and Southern Sydney

In NSW in 1991 the permissible minimum age for buying cigarettes and other tobacco products was raised from 16 to 18 years, with the introduction of the NSW Public Health Act 1991. As part of the information campaign to implement this legislation, a Public Health Act Regulation requires all tobacco vendors to display an official sign warning that tobacco sales to children are illegal. Failure to display the sign carries a penalty of up to $\$ 1,000$, since the display of these signs is considered to be an important means of reducing the availability of cigarettes to children. To assist with implementation of the legislation, on November 21, 1991 the NSW Office of State Revenue issued 20,000 warning signs to licensed tobacco retailers throughout the State. Any unlicensed tobacco retailer would not have received the warning sign. In response to complaints from the public that children were buying and smoking tobacco products, a survey of premises selling cigarettes and tobacco products was conducted in Central and Southern Sydney Health Service Areas to assess whether premises were displaying the warning sign required by the legislation, and if not, why not. The survey was accompanied by education of retailers about the signs.

\section{METHODS}

Tobacco retailers were chosen from shopping centres, railway station kiosks, shops near schools and shops in beachfront malls in Central and Southern Sydney Health Service Areas. Within each Local Government Area, retailers were chosen from one shopping centre, one railway station and from the vicinity of three schools. In shopping centres at least every second tobacco retailer was selected. All tobacco retailers near schools were selected. This process resulted in the selection of 388 retailers.

Each premise was visited between February and September 1992 by an Environmental Health Officer to determine whether the sign was displayed. If a premise did not have the sign displayed, the manager was informed of the legal requirements, and a follow-up warning letter and a copy of the sign were sent.

All premises not displaying the sign at the initial visit were revisited between January and April 1993 to determine whether the sign had been displayed after the initial visit and warning letter. At the second visit, the managers in charge were asked to produce for inspection their licence to sell tobacco. This inspection was confined to premises not displaying the sign because the Office of State Revenue uses the tobacco licence register to mail out warning signs. We therefore assumed that virtually all premises displaying the sign would be licensed.

All data were entered and analysed using Microsoft Excel spreadsheets.

\section{RESULTS}

Of the retailers visited, 120 ( 31 per cent) did not have the sign displayed at the point of sale. The compliance rates were lowest among the most numerous tobacco retailers: take-aways, mixed businesses and newsagents (Table 1). Compliance was also low among the small number of railway kiosks surveyed. Hairdressers, supermarkets and tobacconists generally had high compliance rates. The rate varied widely across Local Government Areas, from 9 out of 10 in Drummoyne to less than half in South Sydney.

During the survey the interest expressed by retailers was low and their cooperation was poor. Some retailers who did not display the sign seemed unconcerned by the warning issued to them. In some cases, comments were made to the effect that the Health Department must have nothing better to do, and in one case the retailer became offensive when told of the penalty for not displaying the sign. In other cases, the claim made was they did not to have time to cooperate.

Non-complying retailers gave various reasons for not displaying the sign (Table 2). The most common was that the sign had been destroyed or lost during cleaning or had fallen off because of accumulation of grease from cooking. This was particularly a problem in take-away businesses, because of cleaning to remove grease from surfaces.

Changes to promotional and advertising material around tobacco stands and refurbishment of stands by tobacco companies were a common reason given for not displaying the sign. Apparently the signs were not being replaced after these alterations. On one visit, a sales representative from a tobacco company had just finished erecting promotional material for a new brand of cigarettes, which had covered the sign. When approached and questioned, he advised that he would obtain a new sign and display it. In other outlets, the same company did not redisplay or replace the sign after completing the same type of work.

Nearly one-quarter of retailers reported they had not received a sign, while others said they were waiting for the tobacco company representative to deliver the sign. Being unable to explain why the sign was not displayed was normally associated with the recent acquisition of a business that did not have the sign.

Following issuing of the warning letters to non-complying retailers, complaints were received by the managers of two newsagencies, who claimed the sign was displayed. On receipt of these complaints the premises were revisited and both managers interviewed. At one premise, the son of the manager, who was in charge of the business at the time, was unable to locate the sign, although he said he remembered having seen it. The sign had been camouflaged by a lottery stand. In the other premise, the assistant was not certain if she had seen the sign in that shop. The sign in this shop was hidden from view by a pile of newspapers.

Most tobacco retailers surveyed said they were aware it is an offence to sell tobacco to children and denied ever doing so.

Among premises which did not have the sign displayed at the initial visit, 86 per cent had the sign displayed at the time of the revisit (Table 3 ). Take-away and mixed businesses were least likely to have the sign displayed after the initial visit/warning letter, although even among these businesses, more than three-quarters were displaying the sign at the time of the revisit. 
More than three-quarters of premises revisited were able to produce a current licence to sell tobacco. Take-away and mixed businesses were least likely to be able to produce a licence to sell tobacco. The most common reasons reported for not having a licence were the belief that a licence was not required or not knowing how to obtain one. Based on the absence of tobacco sales licences in 23 per cent of the 120 premises revisited, we estimate that at least 7 per cent of all premises visited were not licensed to sell tobacco.

\section{DISCUSSION}

While more than two-thirds of tobacco retailers were complying with the law and displaying the official sign warning against sales of tobacco to children, a significant number of retailers were not. If the non-compliance rate observed in this study is representative of the rate throughout NSW, there would be many thousands of tobacco retailers in breach of this law.

Various steps need to be taken to rectify this problem. Tobacco retailers should be reminded of the requirement to display the sign (possibly at the time of payment of the annual tobacco licence fee) and how signs can be obtained. Tobacco retailers such as take-aways could be advised to keep a supply of signs so they can be replaced when destroyed. We found that visiting premises and issuing warning letters was an effective method of increasing compliance, but may be less cost-effective than other methods.

There is also a need for the register of tobacco retailers to be kept up to date and for signs to be given to tobacco retailers not previously sent signs. This study suggests at least 7 per cent of tobacco retailers may be unlicensed.

Follow-up surveys of the type reported here should be undertaken to monitor compliance with the legislation, detect unlicensed retailers, encourage the display of warning signs and educate retailers about not selling tobacco to people under 18 years of age.

\section{TABLE 1}

LEVEL OF COMPLIANCE IN DISPLAYING WARNING SIGN

\begin{tabular}{lccc|}
\hline BUSINESS & PREMISES VISITED & \multicolumn{2}{c|}{$\begin{array}{c}\text { PREMISES NOT } \\
\text { DISPLAYING THE SIGN }\end{array}$} \\
\cline { 3 - 4 } & & 41 & 42 \\
& & 20 & 33 \\
NUMBER & PER CENT \\
\hline Take-away & 97 & 20 & 34 \\
Mixed business & 61 & 7 & 13 \\
Newsagent & 59 & 9 & 24 \\
Supermarket & 53 & 5 & 17 \\
Service station & 38 & 6 & 32 \\
Tobacconist & 29 & 7 & 70 \\
Liquor shop & 19 & 2 & 25 \\
Railway kiosk & 10 & 3 & 38 \\
Cafe & 8 & 0 & 0 \\
Fruit shop & 8 & 120 & 31 \\
Hairdresser & 6 & & \\
\hline Total & 388 & &
\end{tabular}

\section{TABLE 2}

REPORTED REASON FOR NOT DISPLAYING THE WARNING SIGN AMONG 120 PREMISES FOUND TO BE NOT DISPLAYING THE SIGN

\begin{tabular}{|lcc|}
\hline REASON & NUMBER & PER CENT \\
\hline $\begin{array}{l}\text { Sign destroyed or removed } \\
\text { as a result of cleaning }\end{array}$ & 44 & 37 \\
$\begin{array}{l}\text { Sign never received } \\
\text { Sign destroyed during tobacco } \\
\text { stand refurbishment }\end{array}$ & 26 & 22 \\
$\begin{array}{l}\text { Unable to explain why sign } \\
\text { not displayed }\end{array}$ & 20 & 17 \\
$\begin{array}{l}\text { Thought sign was displayed } \\
\text { but unable to locate } \\
\text { Did not know sign was required } \\
\text { to be displayed }\end{array}$ & 15 & 13 \\
\hline Total & 10 & 8 \\
\hline
\end{tabular}

\section{TABLE 3}

LEVEL OF COMPLIANCE IN DISPLAYING WARNING SIGN AND BEING ABLE TO PRODUCE A LICENCE TO SELL TOBACCO AMONG PREMISES REVISITED DUE TO LACK OF THE SIGN AT INITIAL VISIT

\begin{tabular}{|c|c|c|c|c|c|}
\hline \multirow[t]{2}{*}{ BUSINESS } & \multirow[t]{2}{*}{ PREMISES REVISITED } & \multicolumn{2}{|c|}{$\begin{array}{c}\text { PREMISES NOT } \\
\text { DISPLAYING THE SIGN }\end{array}$} & \multicolumn{2}{|c|}{$\begin{array}{l}\text { UNABLE TO PRODUCE } \\
\text { LICENCE }\end{array}$} \\
\hline & & NUMBER & PER CENT & NUMBER & PER CENT \\
\hline Take-away & 41 & 10 & 24 & 12 & 29 \\
\hline Mixed business & 20 & 4 & 20 & 12 & 60 \\
\hline Newsagent & 20 & 2 & 10 & 2 & 10 \\
\hline Supermarket & 7 & 1 & 14 & 1 & 14 \\
\hline Service station & 9 & 0 & 0 & 0 & 0 \\
\hline Tobacconist & 5 & 0 & 0 & 0 & 0 \\
\hline Liquor shop & 6 & 0 & 0 & 0 & 0 \\
\hline Railway kiosk & 7 & 0 & 0 & 0 & 0 \\
\hline Cafe & 2 & 0 & 0 & 0 & 0 \\
\hline Fruit shop & 3 & 0 & 0 & 1 & 33 \\
\hline Hairdresser & 0 & 0 & 0 & 0 & 0 \\
\hline Total & 120 & 17 & 14 & 28 & 23 \\
\hline
\end{tabular}

